\title{
APPLICATION OF ARTIFICIAL NEURAL NETWORK TO PREDICT PROPERTIES OF DIESEL -BIODIESEL BLENDS
}

\author{
Jatinder Kumar*, Ajay Bansal \\ Department of Chemical and Bio Engineering, B R Ambedkar National Institute of Technology \\ Jalandhar-144011 Punjab INDIA \\ *Corresponding author: replytojk@yahoo.com \\ Received 30 December, 2008; Revised 11 January, 2010
}

\begin{abstract}
The experimental determination of various properties of diesel-biodiesel mixtures is very time consuming as well as tedious process. Any tool helpful in estimation of these properties without experimentation can be of immense utility. In present work, other tools of determination of properties of diesel-biodiesel blends were tried. A traditional statistical technique of linear regression (principle of least squares) was used to estimate the flash point, fire point, density and viscosity of diesel and biodiesel mixtures. A set of seven neural network architectures, three training algorithms along with ten different sets of weight and biases were examined to choose best Artificial Neural Network (ANN) to predict the above-mentioned properties of dieselbiodiesel mixtures. The performance of both of the traditional linear regression and ANN techniques were then compared to check their validity to predict the properties of various mixtures of diesel and biodiesel.
\end{abstract}

Key words: Biodiesel, Artificial Neural Network, Principle of least squares, Diesel, Linear Regression.

\section{INTRODUCTION}

Fossil-diesel is depleting very fast and the biodiesel is quickly picking up the market to bridge the gap. Whereas, the biodiesel has the advantage of being potential renewable source of energy, is also known to be non-toxic, eco-friendly, and easy to store and transport and has better lubricity properties [1]. However, it has the disadvantages of high cost compared to petroleum diesel, reduced cold flow properties, detergent characteristics in fuel tank may block fuel ways in the fuel injection system and high viscosity may affect the atomization process in the engine [2]. Biodiesel is completely miscible with diesel oil, thus allowing blends of diesel and biodiesel in any percentage, which may be used in various applications [3]. The various properties of blends like flash point, fire point, viscosity and density are of immense importance as they affect the transportation, storage, handling, atomization and combustion. As such a mixture of diesel and biodiesel in a specified proportion will have different properties than either of pure diesel or biodiesel [4]. It may not always be convenient to make experimentation every time while switching over from one blend to another. Any tool helpful in estimation of these properties without experimentation can be of immense utility. A traditional linear regression analysis using principle of least squares and an Artificial Neural Network (ANN) approach is used in present work to address the problem [5-8]. 
In present work, the method of least squares was examined in order to know its validity to predict the properties of diesel-biodiesel mixtures through curve fitting. A set of seven neural network architectures, three training algorithms along with ten different sets of weight and biases were examined to predict the physical properties of diesel- bidiesel blends. It is of practical importance to make a comparison of both the techniques for selection of a better method of estimation of the mixture properties. The selection of a neural network to a specific problem depends upon the network topology -that is, the number of layers, the size of each layer, and the pattern of connections and the assignment of connection strengths to each pair of connected units and of threshold to each unit [9-13]. In the present study the biodiesel was prepared in the laboratory and the properties of its blends were experimentally measured. A linear regression analysis of the obtained data was made to estimate the properties of diesel-biodiesel blends. A set of seven ANNs with different training algorithms, weights and biases were examined to select the ANN to give the best estimation of properties of diesel-bidiesel blends. The performance of the best neural network was then compared with the traditional least squares method.

\section{MATERIALS AND METHODS}

Biodiesel was prepared from soybean oil by the trans-esterification process, using methanol, in the presence of basic catalyst [14-16]. Different blends were made from the biodiesel and diesel with varying composition. The flash point and fire point were measured using Pensky-Marten Apparatus. The viscosity was measured using Redwood viscometer and calibrated specific gravity bottle was used to measure density. The values of different properties for various blends are shown in Table 1. The values of the properties were used to draw a scattergram between percentages of biodiesel (in diesel-biodiesel mixtures) and corresponding flash point, fire point density and viscosity respectively. A linear relation was observed in each case. The equation of line which best fits was found using principle of least squares in each case. The linear equations obtained were then used to predict the properties of diesel-biodiesel mixtures.

Seven numbers of neural networks having different architecture as shown in Table 2 were used. They were trained with the help of the data available in Table 1 using three training algorithms i.e. Batch Gradient Descent with Momentum, Levenberg-Marquardt and Scaled Conjugate Gradient. The each algorithm with ten different sets of weights and biases was used to train each neural network for 1000 epochs using experimental values of properties as training data. The goal (Mean Square Error) was used to evaluate the performance of each neural network. The combination of neural network architectures, training algorithms, weights and biases with minimum goal was selected as the desired neural network. In order to check its validity the blend properties of fresh samples were predicted using selected neural network and compared with the experimental measurements. The selected neural network was further generalized using early stopping technique to enhance its performance and was further used to predict the properties of diesel and biodiesel mixtures.

\section{RESULTS AND DISCUSSION}

Table 3 summarizes the comparison between the experimental (actual) values of the properties and values of properties predicted using method of least squares. It was found during the study of performance of seven neural networks that the best combination of architecture and training algorithm for the present problem is NN7 (2-7-4) and Levenberg-Marquardt respectively. Table 
4 indicates the comparison between the values predicted by best neural network (i.e. NN7 having best combination of neural network architecture, training algorithm, weights and biases) and the actual values found by laboratory experiments for different mixtures. The selected ANN was then generalized with early stopping technique, in order to avoid over fitting for better performance. Table 5 provides the information about mean square error in prediction of individual properties using principle of least square and generalized neural network. It is clear that individual mean square error is comparatively much less in case of neural network than principle of least squares.

\section{CONCLUSION}

The results show that the ANN is a better choice for this particular system. It is clear from figure 2, 3, 4 and 5 that the predicted and experimental values of the properties have negligibly small error in case of artificial neural network and it gives a better estimation of said properties than statistical technique of cure fitting (principle of least squares). It can be inferred that the neural network NN7 (2-7-4) along with Levernberg-Marquardt algorithm can be a better choice over principle of least squares to predict the above-said properties of various mixtures of diesel and biodiesel. The performance of neural network may further be improved by adjusting the other training parameters like goal, epochs, learning rate, magnitude of the gradient etc.

\section{REFERENCES}

1. Saka S. and Kusdiana D.( 2001) Biodiesel Fuel from Rapeseed Oil as Prepared in Supercritical Methanol, Fuel, 80, 225-31.

2. Graboski, M. S. and McCormick R.L.( 1998), Combustion of Fat and Vegetable Oil Derived Fuels in Diesel Engines, ProgEnergy Comust. Sci., 24, 125-164.

3. Zhang, Y.( 1994), Emissions and Combustion of Fatty Acid Esters of Soybean Oil in a Diesel Engine, M. S. Thesis, Iowa State University.

4. Jacek M.Zurada(2003), Introduction to Artificial Neural Systems. Publishing House, 163248.

5. Venktasubramanian, V. and Vaidyanathan R.( 1990), Fault Detection and Diagonosis using Neural Networks, Computer Chem Engg., 699-712.

6. Mohamad I., and Al- Shyoukh Ali O.( 2002), Experimental Evaluation of The Transesterification of Waste Palm Oil into Biodiesel, Biosource Technology, 85, 253-254.

7. Weiliang Cao (2005), Preparation of Biodiesel from Soyabean Oil using Supercritical Methenol and Co-Solvent, Fuel, 84, 347-351.

8. Kalam M. A., and Masjuki H.( 2002), Biodiesel from Palmoil - An Analysis of Its Properties and Potential, and Bioenergy, 23,471- 479. 
9. Mukherjee A, Thind JK (2003), Cell Prediction of Bacillus through Artificial Neural Network at Simultaneous Multiple Variation in Concentration of Nutrients in Media Proceedings of Indian Chemical Engineering Congress and $56^{\text {th }}$ Annual Session of Indian Institute of Engineers, 16-17.

10. Espinosa G. and Yaffe D. and Cohen Y.(2000), Neural Network based Quantitative Structural Relations (QSPRs) for predicting Boiling Points of Aliphatic Hydrocarbons, J.Chem.Inf .Comput Sci., 40, 859-879.

11. Rosa M. G. and Cesar H.( 2002), Improving Artificial Neural Networks with a Pruning Methodology and Genetic Algorithms for their Applications in Microbial Prediction of Food, Journal of Food Microbiology, 72, 19-30.

12. Hideki F.(2001), Biodiesel Fuel by Transesterification of Oils, Journal of bioscience and bioengineering, 92, 405-416.

13. Kinney A. J. and Clemente T.E.( 2004),Modifying Soyabean Oil Enhanced Performance in Biodiesel Blends, Fuel Processing Technology,XX ,234- 242.

14. Hak-Joo Kim (2004), Trans- esterification of Vegetable Oil Biodiesel Using Heterogeneous Catalyst, Catalyst Today, 93, 315-320.

15. Violeta H.(2005), Solubility of Multi-Component Biodiesel Fuel Systems, Biosource Technology. 96,611-616.

16. Heeb D.( 1949), The organization of behavior Wiley, New York.

17. Rosenblatt F.( 1962), Principles neurodynamics, Spartan New York.

18. Howard H. and Martin K(1989), Protein Secondary Structure Prediction with Neural Network,Proc. NatlAcad.Sci.USA,.86,152-156. 
Table 1 Comparison between actual properties found by experimentation and properties predicted by using principle of least squares.

\begin{tabular}{|c|c|c|c|c|c|}
\hline \multicolumn{2}{|c|}{ Mixture } & \multirow{2}{*}{$\begin{array}{c}\text { Flash Point } \\
\quad\left({ }^{\circ} \mathrm{C}\right)\end{array}$} & \multirow{2}{*}{$\begin{array}{c}\text { Fire Point } \\
\left({ }^{\circ} \mathrm{C}\right)\end{array}$} & \multirow{2}{*}{$\begin{array}{l}\text { Viscosity } \\
\quad \text { (cSt) }\end{array}$} & \multirow{2}{*}{$\begin{array}{r}\text { Density } \\
\text { (g/ml) }\end{array}$} \\
\hline $\begin{array}{c}\text { Biodiesel } \\
(\% \mathrm{v} / \mathrm{v})\end{array}$ & $\begin{array}{c}\text { Diesel } \\
(\% \text { v/v })\end{array}$ & & & & \\
\hline 00 & 100 & 55.4 & 63.0 & 5.27 & 0.8424 \\
\hline 10 & 90 & 55.6 & 66.0 & 6.21 & 0.8459 \\
\hline 20 & 80 & 56.0 & 66.2 & 7.12 & 0.8504 \\
\hline 30 & 70 & 57.2 & 67.0 & 7.40 & 0.8545 \\
\hline 40 & 60 & 58.0 & 69.0 & 7.76 & 0.8583 \\
\hline 50 & 50 & 59.0 & 70.0 & 8.25 & 0.8617 \\
\hline 60 & 40 & 60.1 & 71.2 & 8.93 & 0.8666 \\
\hline 65 & 45 & 61.7 & 73.3 & 9.52 & 0.8692 \\
\hline 70 & 30 & 63.2 & 75.3 & 10.16 & 0.8720 \\
\hline 75 & 25 & 66.4 & 78.2 & 10.41 & 0.8743 \\
\hline 80 & 20 & 70.0 & 81.0 & 10.53 & 0.8746 \\
\hline 85 & 15 & 71.2 & 82.3 & 10.81 & 0.8765 \\
\hline 90 & 10 & 72.0 & 83.2 & 11.07 & 0.8790 \\
\hline 95 & 05 & 76.2 & 85.2 & 11.38 & 0.8819 \\
\hline 100 & 00 & 80.0 & 87.0 & 11.63 & 0.8847 \\
\hline
\end{tabular}

Table 2 Different Neural Network Architecture used.

\begin{tabular}{|c|c|}
\hline Neural Network & Architecture \\
\hline NN1 & $2-1-4$ \\
\hline NN2 & $2-2-4$ \\
\hline NN3 & $2-3-4$ \\
\hline NN4 & $2-4-4$ \\
\hline NN5 & $2-5-4$ \\
\hline NN6 & $2-6-4$ \\
\hline NN7 & $2-7-4$ \\
\hline
\end{tabular}

Table 3 Comparison between actual properties found by experimentation and properties predicted by using principle of least squares

\begin{tabular}{|c|c|c|c|c|c|c|c|c|c|}
\hline \multicolumn{2}{|c|}{ Mixture } & \multicolumn{2}{|c|}{$\begin{array}{c}\text { Flash Point } \\
\left({ }^{\circ} \mathrm{C}\right)\end{array}$} & \multicolumn{2}{|c|}{$\begin{array}{c}\text { Fire Point } \\
\left({ }^{\circ} \mathrm{C}\right)\end{array}$} & \multicolumn{2}{|c|}{$\begin{array}{c}\text { Viscosity } \\
\text { (cSt) }\end{array}$} & \multicolumn{2}{|c|}{$\begin{array}{c}\text { Density } \\
(\mathrm{g} / \mathrm{ml})\end{array}$} \\
\hline $\begin{array}{c}\text { Biodiesel } \\
(\% \mathrm{v} / \mathrm{v})\end{array}$ & $\begin{array}{l}\text { Diesel } \\
(\% \mathrm{v} / \mathrm{v})\end{array}$ & Actual & Predicted & Actual & Predicted & Actual & Predicted & Actual & Predicted \\
\hline 25 & 75 & 56.5 & 56.5 & 66.3 & 66.7 & 7.29 & 7.03 & 0.8523 & 0.8523 \\
\hline 35 & 65 & 57.8 & 58.8 & 67.2 & 69.0 & 7.57 & 7.65 & 0.8563 & 0.8565 \\
\hline 45 & 55 & 58.5 & 61.1 & 69.4 & 71.4 & 8.09 & 8.28 & 0.8594 & 0.8606 \\
\hline 55 & 45 & 59.5 & 63.4 & 70.8 & 73.81 & 8.56 & 8.90 & 0.8640 & 0.8648 \\
\hline
\end{tabular}


Table 4 Comparison between actual properties and properties predicted using ANN

\begin{tabular}{|c|c|c|c|c|c|c|c|c|c|}
\hline \multicolumn{2}{|c|}{ Mixture } & \multicolumn{2}{|c|}{$\begin{array}{c}\text { Flash Point } \\
\left({ }^{\circ} \mathrm{C}\right)\end{array}$} & \multicolumn{2}{|c|}{$\begin{array}{c}\text { Fire Point } \\
\left({ }^{\circ} \mathrm{C}\right)\end{array}$} & \multicolumn{2}{|c|}{$\begin{array}{c}\text { Viscosity } \\
\text { (cSt) }\end{array}$} & \multicolumn{2}{|c|}{$\begin{array}{c}\text { Density } \\
(\mathrm{g} / \mathrm{ml})\end{array}$} \\
\hline $\begin{array}{c}\text { Biodiesel } \\
(\% \mathrm{v} / \mathrm{v})\end{array}$ & $\begin{array}{l}\text { Diesel } \\
(\% \mathrm{v} / \mathrm{v})\end{array}$ & Actual & Predicted & Actual & Predicted & Actual & Predicted & Actual & Predicted \\
\hline 25 & 75 & 56.5 & 56.0 & 66.3 & 66.2 & 7.29 & 7.12 & 0.8523 & 0.8504 \\
\hline 35 & 65 & 57.8 & 57.2 & 67.2 & 67.0 & 7.57 & 7.40 & 0.8563 & 0.8545 \\
\hline 45 & 55 & 58.5 & 58.0 & 69.4 & 68.9 & 8.09 & 7.78 & 0.8594 & 0.8586 \\
\hline 55 & 45 & 59.5 & 61.6 & 70.8 & 73.3 & 8.56 & 9.53 & 0.8640 & 0.8689 \\
\hline
\end{tabular}

Table 5 Mean Square Error after Generalization

\begin{tabular}{|c|c|c|}
\hline \multirow{2}{*}{ Property } & \multicolumn{2}{|c|}{ Mean Square Error } \\
\cline { 2 - 3 } & Least-squares & 0.16 \\
\hline Flash point & 5.74 & 0.74 \\
\hline Fire point & 4.11 & 0.02 \\
\hline Viscosity & 0.06 & $5.54 \mathrm{E}-06$ \\
\hline Density & $5.3 \mathrm{E}-07$ & \\
\hline
\end{tabular}

